\title{
HIV transmission in twin pregnancy: Maternal and perinatal outcomes
}

\author{
LL Makunyane ${ }^{a}, J_{\text {Moodley }}{ }^{\text {* }}$ and MJ Titus ${ }^{c}$
}

\author{
${ }^{a}$ Department of Obstetrics and Gynaecology, Edendale Hospital, Pietermartizburg, South Africa \\ 'Women's Health and HIV Reproductive Group, Department of Obstetrics and Gynaecology, University of KwaZulu-Natal, Durban, South Africa \\ 'Department of Obstetrics and Gynaecology, University of KwaZulu-Natal, Pietermaritzburg, South Africa \\ *Corresponding author, email:jmog@ukzn.ac.za

Background: Despite over two decades of studies of mother-to-child transmission (MTCT) of HIV, very little data is available on HIV transmission in twin pregnancies in Africa.

Objective: To determine transmission rates of the HIV virus between twins and the maternal and perinatal outcomes in HIV positive twin pregnancies.

Methods: An audit involving 186 sets of twin pregnancies delivered at two hospitals in KwaZulu-Natal, South Africa was conducted over a one year period. Relevant data included maternal age, parity, obstetric history, foetal presentation, gestational age at delivery, Apgar scores, birth weight and pregnancy complications.

Results: Of 9521 deliveries, 186 (1.95\%) women were identified with a twin pregnancy; 80 (43\%) of these mothers were HIV infected. One twin was HIV infected giving an incidence of $0.9 \%$. The infected twin was the first-born twin (or twin 1) and was delivered by Caesarean delivery. Based on mode of delivery, there was no transmission for twin 1 or twin 2 via vaginal delivery, but a 1.4\% transmission for twin 1 and $0 \%$ for twin 2 following Caesarean delivery.

Conclusion: Twin pregnancies are at low risk of MTCT of HIV provided the mother is on highly active antiretroviral therapy (HAART) or has taken effective antiretroviral (ARV) treatment (dual therapy) in the antenatal period.

Keywords: HIV transmission, twin pregnancy

\section{Introduction}

Prevention-of-mother-to-child transmission (PMTCT) of HIV is the single most effective medical intervention to reduce the burden of HIV and to achieve goals set by international health organisations to minimise infant and child mortality, and reduce maternal mortality.

It is well known that twin pregnancies are associated with increased rates of obstetric and perinatal complications. ${ }^{2}$ In low and middle income countries (LMIC), twin pregnancies have higher foetal-maternal risks due to a scarcity of human and material resources. ${ }^{2}$ Furthermore, the HIV pandemic in subSaharan Africa increases the risk of maternal and foetal complications associated with twin pregnancies. ${ }^{2}$

There is minimal data on HIV mother-to-child transmission in twin pregnancy worldwide. Mother-to-child transmission rates in singular pregnancies are low. ${ }^{1,3}$ To the authors knowledge, there is no data available on HIV transmission rates in twin pregnancies in South Africa. In addition, our impression is that there may be a difference in HIV transmission rates between twin 1 and twin 2, and in obstetric complications between HIV negative and HIV positive in twin pregnancies. Therefore, the aim of our study was to determine HIV transmission between twin 1 and twin 2, and maternal and perinatal outcomes.

\section{Material and methods}

The study was approved by the Biomedical Research Ethics Committee (ref.164/11) and all women gave informed consent.

This was an audit of 186 women presenting with twin pregnancy for management at two hospitals in KwaZulu-Natal province between 1 May 2013 and 30 April 2014. To ensure that all patients with twin pregnancies were included in the study, the principal author identified twin deliveries from the birth register daily. Written informed consent for inclusion in the study was obtained, and followed up each twin delivery prospectively until discharge from hospital. Counselling on breastfeeding and the need to return in 6 weeks for postnatal care was emphasised. Multiple pregnancies are regarded as high risk and therefore post-delivery follow-ups are done at the hospital, rather than the community clinics. All patients at the hospital site were counselled for HIV testing. A rapid bedside test for HIV was used. If the test was positive, a repeat confirmatory test using a laboratory kit from a different manufacturer was done. If the confirmatory test was positive, a CD4 cell count was done. If the confirmatory test was negative, serum was sent for an ELISA test. All patients with negative tests were re-tested between 32 and 34 weeks.

Patients with CD4 cell count $>350$ cells/ $\mu$ l received ARVs in a fixed dose combination throughout the pregnancy until 1 week following the cessation of breastfeeding. For those patients with CD4 cell count $<350$ cells/ $\mu l$, life-long ARVs were prescribed. All patients were requested to return 6 weeks following delivery, and a HIV PCR test was done on babies born to HIV infected women. Caesarean deliveries (CD) for twin pregnancies were only performed for obstetric indications. Infants were provided with nevirapine prophylaxis per the national guidelines. ${ }^{1}$ Anaemia was defined as a haemoglobin of $<10 \mathrm{~g} / \mathrm{dL}$ while severe anaemia was diagnosed as a haemoglobin below $7 \mathrm{~g} / \mathrm{dL}$.

The relevant data relating to the study were documented which included demographic data pertaining to maternal age, parity, previous obstetric history, foetal presentation of twin pregnancy gestational age at delivery, Apgar scores, birth weight, congenital abnormalities and pregnancy complications. 
Table 1: Demographic and clinical data of HIV uninfected and HIV infected women with twin pregnancies

\begin{tabular}{|c|c|c|c|c|}
\hline Variable & $\begin{array}{c}\text { Total } \\
(n=186)\end{array}$ & $\begin{array}{l}\text { HIV negative } \\
\qquad(n=106)\end{array}$ & $\begin{array}{l}\text { HIV positive } \\
\qquad(n=\mathbf{8 0})\end{array}$ & $p$ value \\
\hline Age (years) & $\begin{array}{c}28.3 \pm 7.0 \\
(15-48)\end{array}$ & $27.07 \pm 7.3$ & $30.0 \pm 6.3$ & $<0.004$ \\
\hline Parity & $1 \pm 1(0-7)$ & $1.2 \pm 1.4$ & $1.6 \pm 1.2$ & $<0.03$ \\
\hline Gravidity & $1 \pm 1(1-8)$ & $2.3 \pm 1.5$ & $2.6 \pm 1.2$ & 0.17 \\
\hline $\begin{array}{l}\text { Antenatal care } \\
\text { visits }\end{array}$ & $\begin{array}{c}6.07 \pm 2.68 \\
(1-15)\end{array}$ & $5.9 \pm 2.7$ & $6.3 \pm 2.7$ & 0.41 \\
\hline \multicolumn{5}{|c|}{ Blood pressure $(\mathrm{mmHg})$ : } \\
\hline Systolic & $\begin{array}{c}115.14 \pm \\
15.07\end{array}$ & $115.9 \pm 15.5$ & $114.5 \pm 14.6$ & 0.3 \\
\hline Diastolic & $68.81 \pm 9.8$ & $68.9 \pm 10.1$ & $68.7 \pm 9.5$ & 0.9 \\
\hline $\begin{array}{l}\text { Gestational } \\
\text { age @ delivery } \\
\text { (weeks) }\end{array}$ & $34.8 \pm 4.5$ & $34.7 \pm 3.5$ & $34.6 \pm 3.6$ & 0.78 \\
\hline
\end{tabular}

The data was analysed with SPSS (version 23). Significance level was set at $p<0.05$.

\section{Results}

There were 9521 deliveries during the study period at the two study sites. Among them, 186 women (mean age: $28.3 \pm 7.01$ ranging from 15-48 years) were identified with twin pregnancies. The incidence of twin pregnancy was $1.95 \%$. Eighty (43\%) patients were HIV positive with mean age $30.0 \pm 6.03$. The demographic clinical characteristics of the study population are shown in Table 1.

We compared the use of ARV therapy between the mothers based on their CD4 cell count. Sixty-eight (85\%) had a CD4 cell count of less than 350 cells/ $\mu$ l and were treated with HAART. Twelve (15\%) had CD4 cell count greater than 350 cells/ $\mu$ land were on dual therapy. In 51 (63.75\%) cases, the patients were on ARV therapy before the current pregnancy while in the remaining 29 cases (36.25\%), the patients started ARV therapy in the current pregnancy at a mean gestational age of 22 (14-28) weeks.

The obstetric complications are shown in Table 2.

Postpartum haemorrhage ( $n=8$ all at CD).

Six patients were HIV positive and two HIV negative. Of these, the underlying and contributing causes of haemorrhage were atonic uterus following vaginal delivery $(n=5)$ and three cases in which there were atonic uterus and surgical difficulties.

\section{Delivery details}

Twenty-two (27.5\%) HIV positive patients delivered vaginally: 39 babies were delivered vaginally and five babies were delivered by $C D$. Those five babies delivered by $C D$ were the second twin (twin 2). Fifty-eight (72.5\%) patients delivered both twins by CD.

One twin was HIV positive giving an incidence of $0.9 \%$. The infected twin was the first-born twin (or twin 1) and was delivered by $C D$. Based on the mode of delivery, there was no transmission for twin 1 or twin 2 via vaginal delivery, but a 1.4\% transmission for twin 1 via CD and $0 \%$ for twin 2. Sixty-eight patients were on ARV therapy at the first antenatal visit. Newly diagnosed antenatal patients $(n=29 ; 36.3 \%)$ received antenatal ARV therapy. On clinical examination of the babies at birth, there was no evidence of congenital abnormalities.
Table 2: Obstetric complications in HIV uninfected and HIV infected women with twin deliveries

\begin{tabular}{|l|c|c|c|c|}
\hline Complications & $\begin{array}{c}\text { Number } \\
(\%)\end{array}$ & $\begin{array}{c}\text { HIV-ve } \\
(n=106)\end{array}$ & $\begin{array}{c}\text { HIV+ve } \\
(n=80)\end{array}$ & $p$ value \\
\hline Preterm labour & $63(33.9)$ & $29(27.4)$ & $34(42.5)$ & 0.03 \\
\hline Anaemia* & $7(3.8)$ & $0(0)$ & $7(8.8)$ & 0.003 \\
\hline $\begin{array}{l}\text { Abruptio } \\
\text { placentae }\end{array}$ & $4(2.2)$ & $3(2.8)$ & $1(1.3)$ & 0.4 \\
\hline $\begin{array}{l}\text { Hypertensive } \\
\text { disorders of } \\
\text { pregnancy }\end{array}$ & $45(24.2)$ & $32(30.2)$ & $13(16.3)$ & 0.02 \\
\hline $\begin{array}{l}\text { Pre-eclampsia } \\
\text { Gestational } \\
\text { hypertension }\end{array}$ & $26(57.2)$ & $19(73.1)$ & $7(26.9)$ & $2(25)$ \\
\hline $\begin{array}{l}\text { Severe pre- } \\
\text { eclampsia }\end{array}$ & $11(24.4)$ & $7(63.6)$ & $4(36.4)$ & \\
\hline
\end{tabular}

" 3 cases of severe anaemia in the HIV infected group was ART (zidovudine) related.

Anaemia $(<10 \mathrm{~g} / \mathrm{dL})$ was present in $42.5 \%(n=34)$ of patients.

\section{Postdelivery data}

Twenty-three (28.75\%) patients in the HIV infected group were breastfeeding. Fifty-eight (72.5\%) of the 80 HIV infected patients returned at 6 weeks with their babies for DNA PCR test. One patient returned with only one baby (twin 2). One hundred and fourteen PCR tests were negative for both twin 1 and twin 2. In one case the PCR in the surviving twin 1 was positive.

\section{Discussion}

The incidence of twin pregnancy is variable worldwide ranging from $1-4.5 \%{ }^{4}$ Our twin birth rate was $1.95 \%$ compared to a $3.2 \%$ from Nigeria; ${ }^{5} 3.6 \%$ from Greece; ${ }^{6} 2.1 \%$ from France; ${ }^{7} 1.49 \%$ from India, ${ }^{8} 1.8 \%$ in Guinea-Bissau; ${ }^{9}$ and $1.5 \%$ from Italy. ${ }^{10}$

The prevalence of HIV in twin pregnancy was $43 \%(n=80)$. This figure is in keeping with rates of HIV for singleton pregnancies in the study site hospital (40\%), but much higher than the national average of $29 \%$. $^{1}$

Several studies have shown conflicting results regarding HIV transmission rates in twin 1 and twin 2. Goedert et al. showed that transmission rate of HIV infection was greater in twin 1 compared to twin $2 .{ }^{11}$ These authors found that the transmission rate for the firstborn baby (14/164) was threefold greater than the second born baby (14/164 vs. $4 / 164 ; p=0.008)$. Furthermore, the transmission rate of HIV in twin 1 was greater $(50 \%)$ during vaginal delivery compared to $38 \%$ delivered by CD. In twin 2, the transmission was $19 \%$ for those delivered either vaginally or by CD. Similarly, Biggar et al. found no difference in MTCT between twin $1(6.3 \%)$ compared to twin $2(6.0 \%)$ in the second born. ${ }^{12}$ Duliege et al. studied the MTCT based on mode of delivery; they found that MTCT in twin 1 occurred in $35 \%$ via the vaginally delivered versus $16 \%$ via CD. ${ }^{13}$ For the twin 2 , the MTCT rate was $15 \%$ via the vaginal route and $8 \%$ via $\mathrm{CD}$. Scavalli et al. showed that the transmission rate of HIV infection was three-fold greater in twin 1 than in twin $2 .^{7}$

In our study, one twin was infected with HIV resulting in an incidence of $0.9 \%$. The infected twin was the first-born twin (or twin 1) and was delivered by CD. Based on mode of delivery, there was no transmission for twin 1 or twin 2 via vaginal delivery, but a $1.4 \%$ transmission for twin 1 via $C D$ and $0 \%$ for twin 2 . The low incidence of MTCT could be due to our successful implementation of PMTCT programme. Konte et al. reported that 
7/191 of all deliveries were twins..$^{6}$ In two out of seven pregnancies, the new born received no neonatal prophylaxis; MTCT took place in three of the four infants; while HIV was diagnosed intrapartum for five of the seven pregnancies, however implementation of appropriate intervention of MTCT was $0 \%$.

The rate of complications associated with a twin pregnancy are high for both mother and infants. ${ }^{14}$ In our study there were eight cases of postpartum haemorrhage (PPH) and one maternal death. It is well known that multiple pregnancies are more prone to develop PPH due to over-distension of the uterus. Therefore, clinical protocols suggest that great care needs to be taken immediately post-delivery to observe for vaginal bleeding and to ensure that the uterus remains contracted. This may not have been done in the case of maternal death in our study. Surgical difficulties were identified in two cases. This underlines the increased complication rates associated with twin pregnancy delivered via CDs and, being high-risk pregnancies, must be delivered by experienced surgeons.

The incidences of congenital abnormalities are increased in twin pregnancies. ${ }^{15}$ In our audit, the prevalence of congenital abnormalities was $2.7 \%$ compared to $9.5 \%$ reported previously. ${ }^{16}$ Our lower prevalence may be due to the small numbers of twin pregnancies in our study.

The incidence of hypertensive disorders of pregnancy is said to be high in twin pregnancy, ${ }^{17}$ with the reported incidence of preeclampsia two to three times higher in twin pregnancies than singleton pregnancies. ${ }^{18}$ Results of a large prospective trial demonstrated that women with a twin gestation complicated by gestational hypertension or pre-eclampsia were more likely to have a pregnancy that resulted in a preterm delivery, a low birth weight infant, or a CD. ${ }^{18}$ We report similar findings. We also found that pre-eclampsia was more common in HIV negative women than HIV positive women. In an earlier study, Kalumba et al. showed that the rate of HIV/AIDS was significantly lower in women with pre-eclampsia than in normotensive healthy pregnant women. ${ }^{19}$ The issue of whether HIV impacts on the frequency of pre-eclampsia has not been resolved and further study involving a large number of participants is needed.

It is surprising that the prevalence of anaemia was approximately $3.8 \%$ and all cases of anaemia were in the HIV positive group. It is well accepted that the prevalence of anaemia in LMIC is high. Tunkyi et al. showed the prevalence of anaemia in pregnancy in a regional hospital in Durban was approximately $42 \%{ }^{20}$ It is plausible that the twin pregnancies being high-risk patients were more adherent to folic acid and iron prophylaxis and treatment. Furthermore, our cut-off level for haemoglobin estimation was $10 \mathrm{~g} / \mathrm{dL}$. It has been reported that HIV infection is probably an independent factor and less likely to be due to HIV ARV therapy. ${ }^{21}$ None of our patients were on zidovudine therapy, a drug specifically reported to be associated with anaemia. ${ }^{21}$

The limitations of our study were the small number of HIV infected twin pregnancies studied. Secondly, only $58 \mathrm{HIV}$ infected patients returned for PCR test.

In conclusion, the overall incidence of MTCT of HIV was $0.9 \%$. The incidence of MTCT in the twin 1 was $1.4 \%$ and $0 \%$ in twin 2 . Based on mode of delivery, there was no transmission for twin 1 or twin 2 via vaginal delivery but a $1.4 \%$ transmission for twin 1 via $C D$ and $0 \%$ for twin 2.Twin pregnancies are not atan increased risk of HIV transmission if appropriate antenatal antiretroviral treatment is prescribed.

\section{References}

1. The 2012 National Antenatal Sentinel HIV Herpes Simplex Type-2 Prevalence Survey in South Africa. National Department of Health, Pretoria. 2013. Available from: https://www.health-e.org.za/wp content/uploads/2014/05/ASHIVHerp Report2014 22May2014.pdf

2. Ganchimeg T, Morisaki N, Vogel JP, et al. Mode and timing of twin delivery and perinatal outcomes in low- and middle-income countries: a secondary analysis of the WHO Multicountry Survey on Maternal and Newborn Health. BJOG. 2014;121(suppl 1):89-100. doi:10.1111/1471-0528.12635.

3. Townsend $\mathrm{CL}$, Byrne $\mathrm{L}$, Cortina-Borja $\mathrm{M}$, et al. Earlier initiation of ART and further decline in mother-to-child HIV transmission rates, 2000-2011. AIDS. 2014;28(7):1049-57. http://dx.doi.org/10.1097/ QAD.0000000000000212

4. Edwards RG, Mettler L, Walters DE. Identical twins and in -vitro fertilization. J In Vitro Fertil Embryo Transf. 1986;3:114-7. http:// dx.doi.org/10.1007/BF01139357

5. Akaba GO, Agida TE, Onafowokan $\mathrm{O}$, et al. Review of twin pregnancies in a tertiary hospital in Abuja, Nigeria. J Health Pop Nutr. 2013;31(2):272-7.

6. Nikolopoulos G, Konte V, Masqala A, et al. Surveillance data on paediatric HIV infection and AIDS in Greece. Euro Surveill. 2004;9(9):9-11.

7. Scavalli $C P$, Mandelbrot L, Berrebi A, et al. Twin pregnancy as a risk factor for mother-to-child transmission of HIV-1: trends over 20 years. AIDS. 2007;21(8):993-1002. http://dx.doi.org/10.1097/ QAD.0b013e3281532b19

8. Bangal VB, Patel SM, Khairnar DN. Study of Maternal and fetal outcome in twin gestation at tertiary care teaching hospital. Int J Biomed Adv Res. 2012;3(10):758-62.

9. Bjerregaard-Andersen $M$, Lund $N$, Jepsen $F S$, et al. $A$ prospective study of twinning and perinatal mortality in urban Guinea-Bissau. BMC Pregnant Childbirth. 2012;12:140. http://dx.doi.org/10.1186/1471-2393-12-140

10. de Martino M, Tovo PA, Galli L, et al. HIV-I infection in perinatally exposed siblings and twins. The Italian Register for HIV Infection in Children. Arch Dis Child. 1991;66(10):1235-8. http://dx.doi.org/10.1136/adc.66.10.1235

11. Goedert JJ. High risk of HIV-1 infection for first-born twins. Lancet. 1991;338(8781):1471-5. http://dx.doi.org/10.1016/0140-6736(91)92297-F

12. Biggar RJ, Cassol S, Kumwenda N, et al. The risk of human immunodeficiency virus-1 infection in twin pairs born to infected mothers in Africa. J Inf Dis. 2003;188(6):850-5. http://dx.doi org/10.1086/jid.2003.188.issue-6

13. Duliège $\mathrm{AM}$, Amos $\mathrm{Cl}$, Felton $\mathrm{S}$, et al. Birth order, delivery route, and concordance in the transmission of human immunodeficiency virus type 1 from mothers to twins. J Pediatr. 1995;126(4):625-32. http://dx.doi.org/10.1016/S0022-3476(95)70365-9

14. Devine PC, Malone F. Maternal complications associated with multiple pregnancy. Clin Obstet Gynaecol. 2004;47:227-36. http://dx.doi.org/10.1097/00003081-200403000-00023

15. Sun LM, Chen XK, Wen SW, et al. Perinatal outcomes of normal cotwins in twin pregnancies with one structurally anomalous fetus: a population-based retrospective study. Am J Perinatol. 2009;26:51-6. http://dx.doi.org/10.1055/s-0028-1095180

16. Allen SR, Gray LG, Frentzen BH, et al. Ultrasonographic diagnosis of congenitalanomaliesintwins. AmJObstetGynecol.1991;165:1056-60. http://dx.doi.org/10.1016/0002-9378(91)90469-8

17. Bush MC, Pernoll ML. Multiple pregnancy. In: Decherney $A H$, editor. Current diagnosis and treatment in obstetrics and gynaecology. 10th ed. New York (NY): McGraw Medical Publishing Division; 2007. p. 310

18. Sibai B, Hauth J, Caritis S. Hypertensive disorders in twin versus singleton gestations. Am J Obstet Gynecol. 2000;182:938-42. http://dx.doi.org/10.1016/S0002-9378(00)70350-4

19. Kalumba VMS, Moodley J, Naidoo TD. Is the rate of pre-eclampsia affected by HIV/AIDS? Cardiovasc J Africa. 2013;24(1):21-5.

20. Tunkyi K, Moodley J. Prevalence of anaemia in pregnant in a regional health facility in South Africa. S Afr Med J 2016;106(1):101-4 doi: 10.7196/SAMJ.2016.v10611.9860.

21. Nandlal V, Moodley D, Grobler A, et al. Anaemia in pregnancy is associated with advanced HIV disease. PLOS One. 2014 September 15;9(9):1-6, e106103. doi: 10.1371/journal.pone.0106103. 